\title{
The development of a new type of winder
}

\author{
$\mathrm{XieLu}^{1, \mathrm{a}}$, Liu Yangyang ${ }^{1, \mathrm{~b}}$ \\ ${ }^{1}$ No.3 Oil Production Plant, Saltu District, Daqing, Heilongjiang Province
}

\begin{abstract}
Oilfield testing. This paper introduces a new type of wire spinner developed by TRIZ Method. The machine is ingenious in conception, shortens the working time of workers and achieves certain economic benefits.
\end{abstract}

\section{Preface}

Layered testing of water injection wells in oilfield is to measure the water absorption of each water injection interval under different pressures by using testing instruments. It is an important means to understand the water absorption capacity of the reservoir, identify the accuracy of layered water distribution scheme, check whether the packer is sealed, whether the water distributor works normally, and the construction quality of downhole operation. [1] During the test, the logging wire is required to lower the assembled instrument string to the bottom of the well. After the layered flow test operation is completed, the test winch is started and the steel wire is wound on the winch drum until the instrument string is lifted to the wellhead. In order to ensure the steel wire to be worn and damaged in time, the most common form of steel wire is to replace the steel wire in time. It is a very timeconsuming and laborious work to take out and recycle the old steel wire (cable).

\section{Solving problems with TRIZ Method}

\section{1 system analysis causal chain analysis [2]}

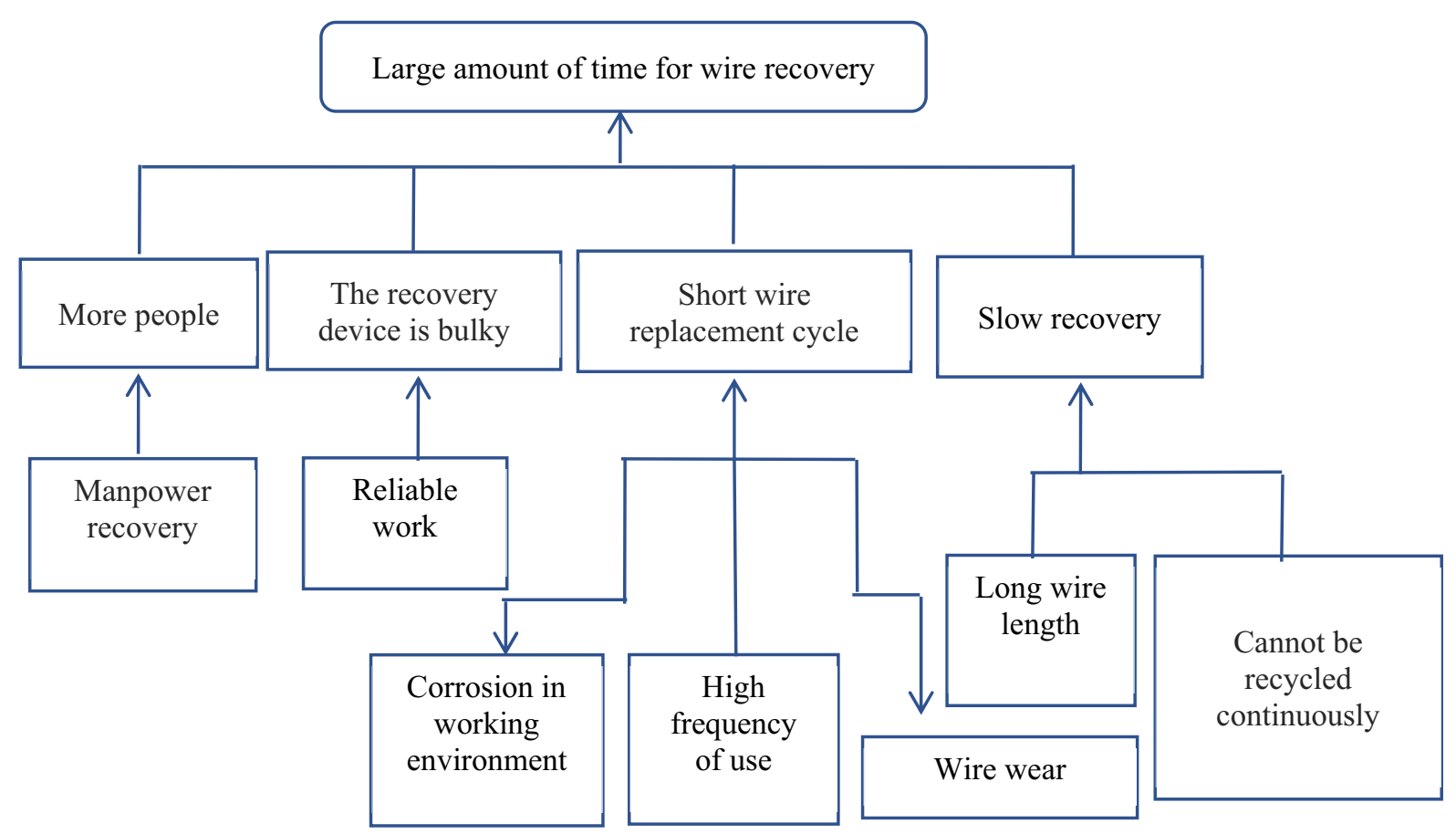

Figure1. 
By applying the causal chain analysis of TRIZ system analysis, we get the conclusion that the mechanical power recovery device is used, the base of the recovery device is removed, the bolt is used to fix the recovery device, the detachable baffle is used for the drum of the recovery device, and the conical drum is used for the recovery

Table1.

device. There are five technical solutions: using cheap roller, discarding and not reusing after recycling wire.

\subsection{TRIZ tool -- final ideal solution [2]}

\begin{tabular}{|c|c|}
\hline IFR implementation deduction 6 steps & Analysis results \\
\hline 1. What is the ultimate goal of design? & There is no need to recycle wire \\
\hline 2. What is the final ideal solution of the problem? & The wire can be used indefinitely without replacement \\
\hline 3. What are the obstacles to the ideal solution? & $\begin{array}{l}\text { 1. The wire rod has its own defects } \\
\text { 2. The wire rod is worn during use } \\
\text { 3. The working environment of wire rod is corrosive }\end{array}$ \\
\hline 4. What are the results / reasons for this disorder? & $\begin{array}{l}\text { 1. Unqualified wire quality } \\
\text { 2. Friction contact between wire rod and pulley, roller, etc } \\
\text { 3. Contact between wire rod and downhole fluid }\end{array}$ \\
\hline 5. What are the conditions for the absence of such obstacles? & $\begin{array}{l}\text { The quality of wire rod is qualified, and it is not in contact with } \\
\text { other substances }\end{array}$ \\
\hline $\begin{array}{l}\text { 6. What are the resources available to create these } \\
\text { conditions? }\end{array}$ & Information resources, protective grease \\
\hline
\end{tabular}

By using the "final ideal solution", we have got two technical solutions: to do a good job in detection before using wire rod, to avoid using unqualified wire rod, and to

\subsection{TRIZ tools - information interaction theory [2]} continuously apply protective grease in the process of using wire rod.

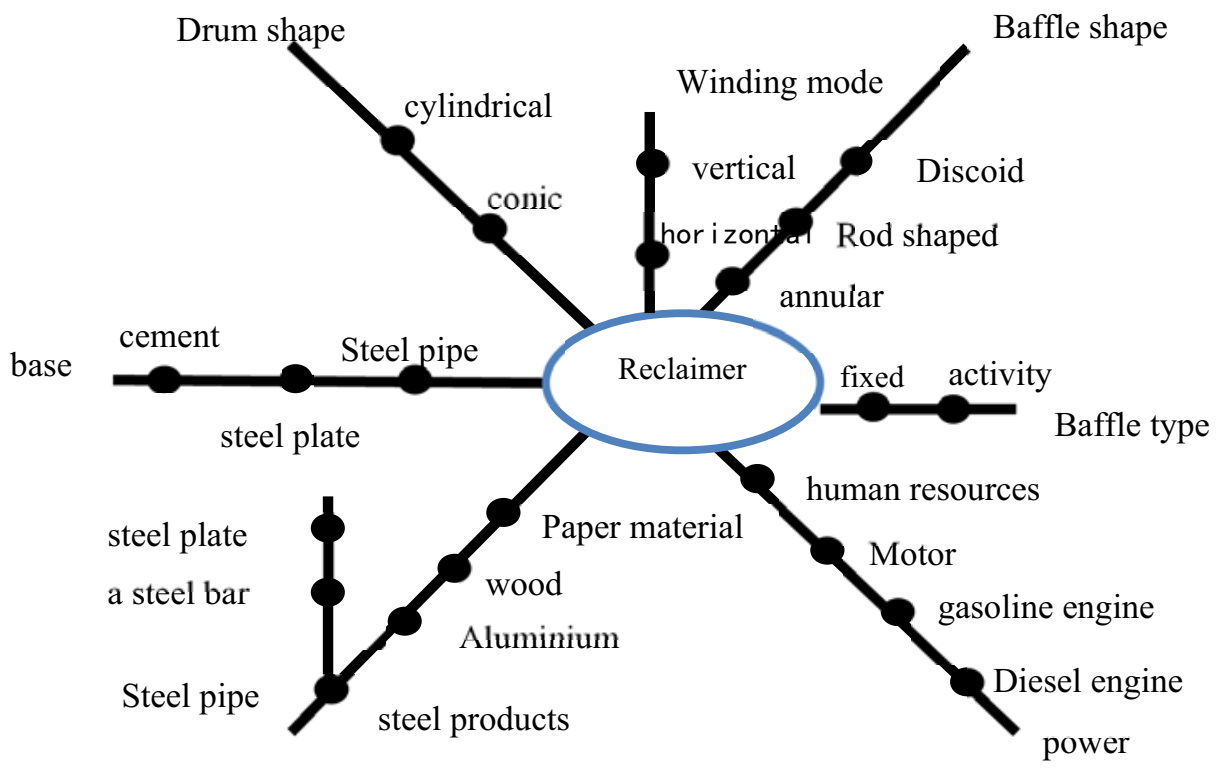

Roller material

Figure2.On information interaction

According to the theory of information interaction, we put forward the use of electric fixed baffle cylinder paper drum, the drum after winding waste wire is not recycled; the use of electric packaging wire rod wooden roller, the drum after winding waste wire is not recycled; the use of electric aluminum cone-shaped movable baffle drum; the use of electric steel bar cone-shaped drum rod baffle drum; the use of human horizontal steel pipe base without baffle recycler And so on. 


\subsection{Using TRIZ Method to solve problem technical contradiction [2]}

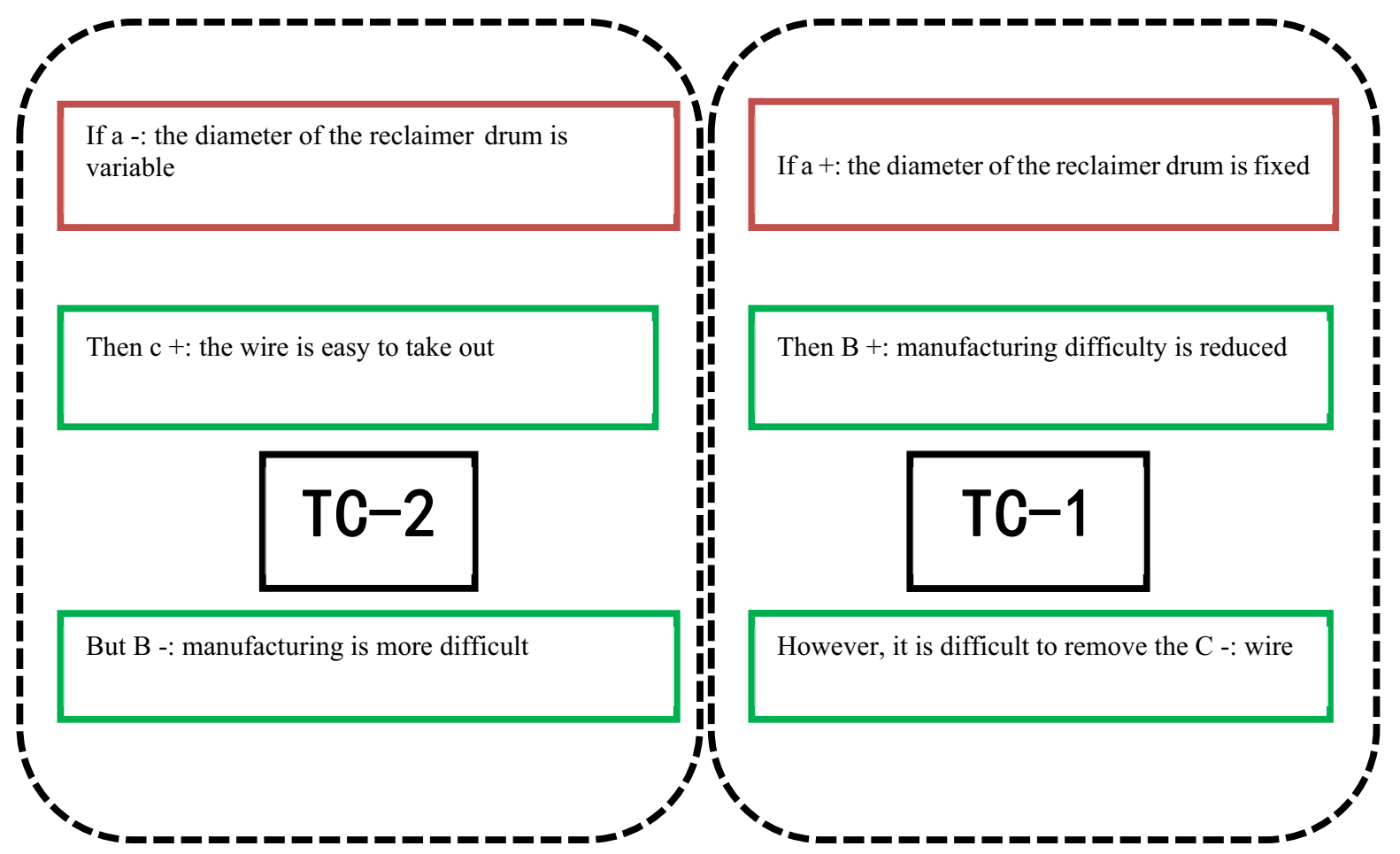

Figure3.Technical contradictions

It is determined that the technical contradiction to be solved is TC-2, which occurs between the difficulty of taking out the wire rod and the manufacturing difficulty of the drum, and occurs under the condition that the diameter of the recycling drum is variable. In the problem model, the improved parameter is the workload of wire removal, and the worse parameter is the difficulty of drum manufacturing. In the scheme model, we found four TRIZ invention principles: 35 performance conversion method, 15 dynamic method, 34 self generation and self abandonment method, and 18 mechanical vibration method. This paper puts forward the perfect solution that the shape of the roller shaft of the reclaimer changes from cylinder to cone after recovering wire rod.

\subsection{Using TRIZ Method to solve problem physics contradiction [2]}

The physical contradictions of the wire rod collector are: the diameter of the drum should be fixed to meet the requirements of easy manufacturing; the diameter of the drum should be variable to meet the requirements of easy removal of the wire rod; according to the principle of space separation and time separation in the physical contradiction, it can be put forward that the drum winding shaft is composed of four steel bars; the drum baffle plate is divided into two parts; one end of the steel bar is hinged, and the other end is flexible Three programs of free movement.

\section{Application of achievements}

Four steel rods are evenly distributed around the circumference to form a spool. One end of each steel rod is hinged and fixed at one end of the reel. When in use, the four steel rods pass through the baffle plate and support plate, and then screw in the nuts to fix them. The device is designed with a power distribution system, which can adjust the speed arbitrarily. After the wire is coiled, the support plate is removed. The four steel rods will slide down along the long hole of the baffle plate due to the wire pressure, and the spool formed will shrink and deform. The coiled wire rod can be easily removed and recycled.

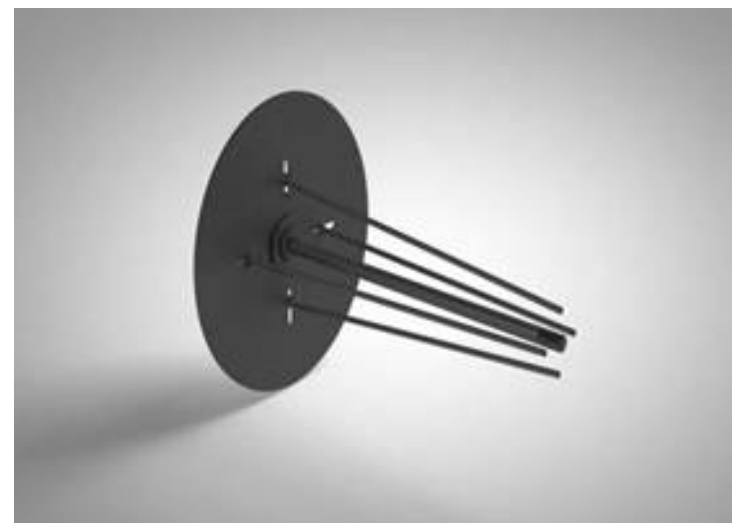




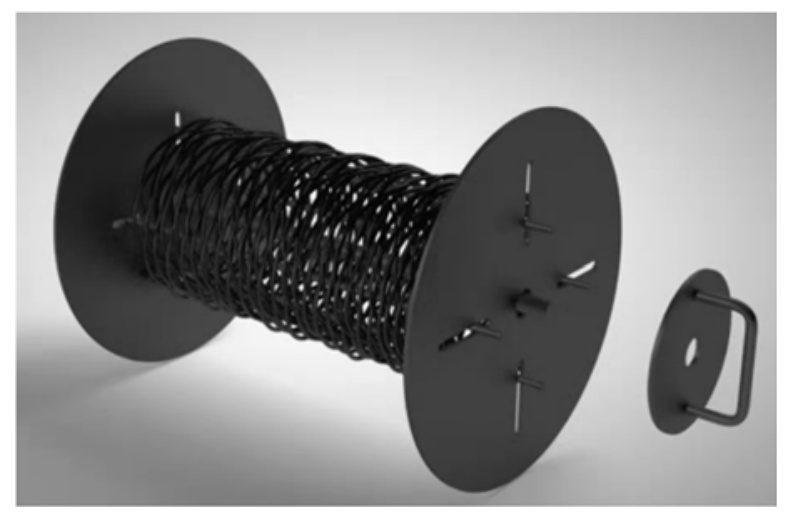

\section{Main innovations}

The device skillfully designs a movable steel rod as a reel, which changes into a cone after removing the support, so as to solve the problem that the wire rod is difficult to take off.

\section{Conclusion}

The device has the advantages of small volume, light weight, convenient movement, low manufacturing cost and safe and reliable use. It can effectively reduce the labor intensity, improve the work efficiency, and shorten the time of recycling wire rod from 2 hours to 37 minutes.

\section{Author brief introduction}

XieLu (1975- ), male, Heilongjiang people of the people's Republic of China, Oil production engineer of PetroChina Daqing Oilfield Co., Ltd, Bachelor of Engineering, Tel:13936965892,

LiuYangyang (1987- ), female, Heilongjiang people of the people's Republic of China, Assistant oil production engineer of PetroChina Daqing Oilfield Co., Ltd, Bachelor of Engineering, Tel: 15846938059.

\section{References}

1. Wan Renpu Oil Production Engineering Manual [M]. Petroleum Industry Press, 2003.3

2. Research Committee on Innovative Methods, China Agenda 21 Management Center Compiles Course on Innovative Methods (Primary) Higher Education Press, May 2012 